\begin{tabular}{|c|c|c|}
\hline \multirow{3}{*}{$\begin{array}{r}\text { Case Reports in } \\
\text { Gastroenterology }\end{array}$} & \multirow{2}{*}{\multicolumn{2}{|c|}{ Case Rep Gastroenterol 2014;8:115-118 }} \\
\hline & & \\
\hline & $\begin{array}{l}\text { DOI: } 10.1159 / 000362225 \\
\text { Publisned online: March 28, } 2014\end{array}$ & $\begin{array}{l}\text { ○ } 2014 \text { S. Karger AG, Basel } \\
\text { 1662-0631/14/0081-0115 } \$ 39.50 / 0 \\
\text { www.karger.com/crg }\end{array}$ \\
\hline & \multicolumn{2}{|c|}{$\begin{array}{l}\text { This is an Open Access article licensed under the terms of the Creative Commons } \\
\text { Attribution-NonCommercial } 3.0 \text { Unported license (CC BY-NC) (www.karger.com/OA } \\
\text { license), applicable to the online version of the article only. Distribution permitted for non } \\
\text { commercial purposes only. }\end{array}$} \\
\hline
\end{tabular}

\title{
A Differential Diagnosis for Left Atrial Mass on Transthoracic Echocardiography: Hiatus Hernia
}

\author{
Harshil Dhutia \\ St George's University, London, UK
}

\section{Key Words}

Hiatus hernia · Cardiac mass · Echocardiography

\begin{abstract}
Hiatus hernia is a common medical condition. An elderly woman being investigated for dyspnoea of unknown aetiology had a transthoracic echocardiogram as part of her investigations. This alarmingly demonstrated a large left atrial mass. Further assessment with cardiac magnetic resonance imaging revealed a large hiatus hernia compressing the left atrium and no intra-cardiac mass. The case succinctly highlights gastrointestinal pathology simulating cardiac symptoms and masses.

(C) 2014 S. Karger AG, Basel
\end{abstract}

\section{Introduction}

Transthoracic echocardiography is a commonly performed non-invasive investigation of cardiac anatomy and physiology and is indicated for the diagnosis of common cardiac pathologies. These include valvular heart disease, ischaemic heart disease, cardiomyopathies and infective endocarditis, to name a few. Echocardiography is also indicated in the diagnosis and assessment of intra-cardiac masses, but additional investigations may be required to evaluate them further. It is recognised that non-cardiac pathology can present with cardiac symptoms and artefact on cardiovascular investigations [1-5].

We present the case of a patient diagnosed with hiatus hernia presenting with cardiovascular symptoms and appearance of intra-cardiac mass on transthoracic echocardiography, and also review the relevant literature. 
Dhutia: A Differential Diagnosis for Left Atrial Mass on Transthoracic Echocardiography: Hiatus Hernia

\section{Case Presentation}

An 81-year-old female with a background of stable ischaemic heart disease and hypertension was referred to the cardiology department complaining of dyspnoea on exertion over a period of 12 months. This was more appreciable on inclines. She did not suffer from chest pain, orthopnoea, ankle swelling or syncope. She denied fever, weight loss, change in appetite, dyspepsia or gastrointestinal bleeding. Her medication list included aspirin, a statin, a proton-pump inhibitor and an angiotensin receptor blocker. There was no significant family history and she was a non-smoker.

Physical examination was normal; in particular there were no finger clubbing, no cardiac murmurs on auscultation and no signs of fluid retention such as elevated jugular venous pressure and peripheral oedema. Resting electrocardiography demonstrated normal sinus rhythm. Her haemoglobin, leukocyte count, renal and liver function blood tests were all normal. B-type natriuretic peptide was within normal limits.

Given her past medical history of cardiovascular disease, she was referred for echocardiography to assess for structural or functional cardiac disease possibly contributing to her unexplained dyspnoea. Transthoracic echocardiography using standard views was performed. Alarmingly, the study demonstrated a large echolucent mass with the appearance of a left atrial space-occupying lesion (fig. 1). Left ventricular size and contractile function were preserved and there was no significant valvular disease. Right ventricular size and function were normal and there was no pericardial effusion.

To further delineate the intra-cardiac mass, the patient underwent cardiac magnetic resonance imaging (MRI). The study revealed no intra-cardiac masses, with normal heart structure and function. It demonstrated a large hiatus hernia containing food and compressing and distorting the posterior wall of the left atrium (fig. 2).

The patient has been referred on for surgical correction of her hiatus hernia.

\section{Discussion}

Although often asymptomatic, hiatus hernia can present with symptoms mimicking those of cardiovascular pathology such as dyspnoea [4], chest pain [1] and syncope [5]. Furthermore, by cardiac compression, hiatus hernia can produce dynamic electrocardiography changes [6] and simulate the appearances of cardiac masses on echocardiography [1-4].

Our patient presented with symptoms of breathlessness and was suspected of having congestive cardiac failure, given a past history of ischaemic heart disease and hypertension. Left atrium compression can lead to symptoms mimicking congestive heart failure. It is believed that extrinsic compression of the left atrium results in these symptoms due to impaired left atrial filling leading to pulmonary venous hypertension [7]. A case series of patients with significant left atrial compression by gastric structures presenting with haemodynamic instability and respiratory failure has been reported [8].

The differential diagnosis of an intra-cardiac mass includes tumours (benign or malignant), thrombi, vegetation, normal anatomical variants (such as Eustachian valve, Chiari network, etc.) and artefact. Hiatus hernia mimicking intra-cardiac mass due to sonographic artefact was diagnosed in this case using multi-modality imaging. Although transthoracic echocardiography is an excellent initial diagnostic technique to evaluate and diagnose cardiac masses, invariably definitive diagnosis and comprehensive view of these structures is confirmed by other imaging modalities such as cardiac MRI, through the excellent spatial resolution and range of sequences of this modality to characterize tissue. Cardiac MRI 
Dhutia: A Differential Diagnosis for Left Atrial Mass on Transthoracic Echocardiography: Hiatus Hernia

has been found to have greater efficacy in the detection and morphological evaluation of cardiac masses compared to echocardiography, which may be limited by poor sonographic windows [9].

Hiatus hernia has a high prevalence. The growing number of indications for performing echocardiography will undoubtedly result in misdiagnosis of cardiac masses in these patients, irrespective of symptoms. This in turn will have implications for the patient as well as for clinical resources.

In conclusion, as highlighted by this case, one should consider extra-cardiac pathology such as hiatus hernia in the assessment of cardiac masses demonstrated on echocardiography, and appreciate that these can present with symptoms resembling those from primary cardiac disorders.

\section{Ethics}

The patient presented in this report gave informed consent to her case being submitted for publication and is aware that there are no patient-identifying details in the text or images submitted. The case met all local ethical protocols.

\section{Disclosure Statement}

The author has no conflict of interest.

\section{References}

1 Koskinas KC, Oikonomou K, Karapatsoudi E, Makridis P: Echocardiographic manifestation of hiatus hernia simulating a left atrial mass: case report. Cardiovasc Ultrasound 2008;6:46.

-2 Chan J, Manning WJ, Appelbaum E, Smith P, Rice K: Large hiatal hernia mimicking left atrial mass: a multimodality diagnosis. J Am Coll Cardiol 2009;54:569.

3 Parsai C, Perrenoud J: Left atrial mass or hiatus hernia: value of cardiac MRI. Heart 2011;97:344

4 Pellicori P, Sherwi N, Khaleva O, Wong K, Cleland JG: An atrial mass: the value of echocardiographic three-dimensional reconstruction. J Cardiovasc Med (Hagerstown) 2012;13:769-770.

5 Oishi Y, Ishimoto T, Nagase N, Mori K, Fujimoto S, Hayashi S, Ochi Y, Kobayashi K, Tabata T, Oki T: Syncope upon swallowing caused by an esophageal hiatal hernia compressing the left atrium: a case report. Echocardiography 2004;21:61-64.

-6 Hokamaki J, Kawano H, Miyamoto S, Sugiyama S, Fukushima R, Sakamoto T, Yoshimura M, Ogawa H: Dynamic electrocardiographic changes due to cardiac compression by a giant hiatal hernia. Intern Med 2005;44:136-140.

7 DeLuca A, Daniels S, Pathak N: Pulmonary edema due to extreme left atrial compression. N J Med 1991;88: 37-38.

8 Raza ST, Mukherjee SK, Danias PG, Abraham J, Johnson KM, Sands MJ Jr, Werner MS, Silverman DI: Hemodynamically significant extrinsic left atrial compression by gastric structures in the mediastinum. Ann Intern Med 1995;123:114-116.

-9 Gulati G, Sharma S, Kothari SS, Juneja R, Saxena A, Talwar KK: Comparison of echo and MRI in the imaging evaluation of intracardiac masses. Cardiovasc Intervent Radiol 2004;27:459-469. 


\begin{tabular}{l|l}
\hline Case Rep Gastroenterol 2014;8:115-118 \\
\hline DOI: 10.1159/000362225 & $\begin{array}{l}\text { ○ 2014 S. Karger AG, Basel } \\
\text { www.karger.com/crg }\end{array}$ \\
\hline
\end{tabular}

Dhutia: A Differential Diagnosis for Left Atrial Mass on Transthoracic Echocardiography: Hiatus Hernia

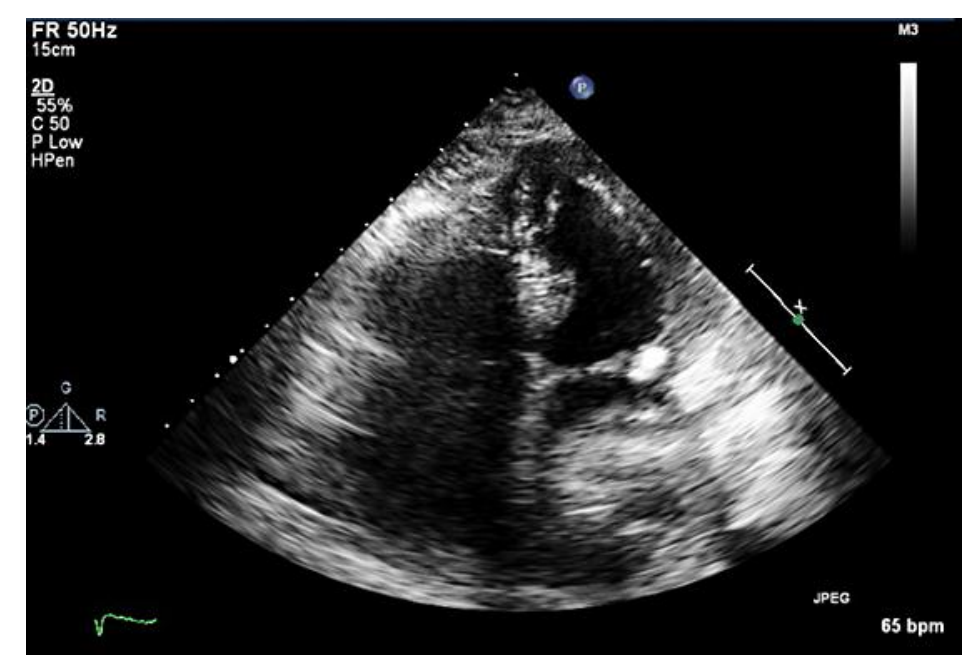

Fig. 1. Apical four-chamber transthoracic echocardiography view demonstrating the appearance of a large mass in the left atrium.

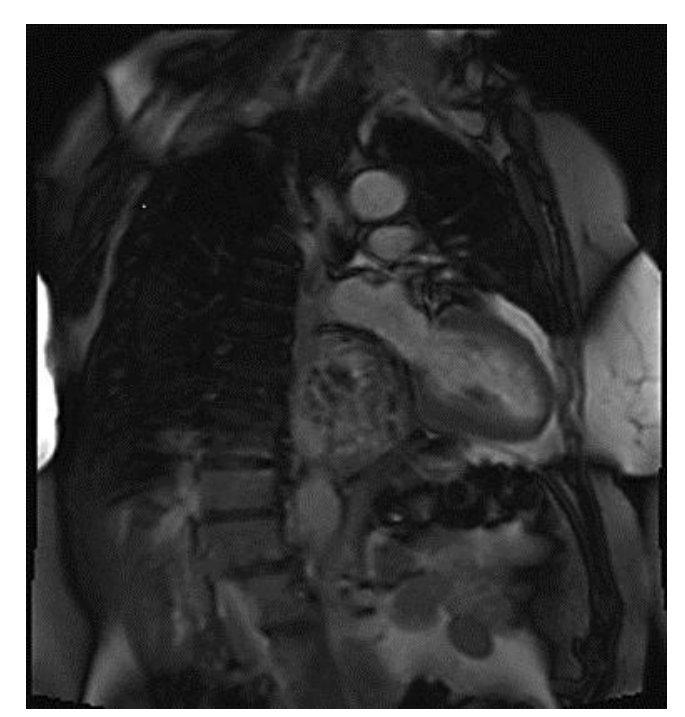

Fig. 2. Cardiac MRI study demonstrating a large hiatus hernia compressing and distorting the posterior wall of the left atrium. No intra-cardiac mass was identified. 


\section{Erratum}

In the article by Dhutia $\mathrm{H}$, entitled 'A differential diagnosis for left atrial mass on transthoracic echocardiography: hiatus hernia' [Case Rep Gastroenterol 2014;8:115-118, DOI: 10.1159/000362225], the following two authors need to be added: Felix Gill and Zak Vinnicombe. The authors should therefore read: Dhutia H, Gill F and Vinnicombe Z. 